\title{
Unusual Spontaneous Nasal Septal Abscess
}

\author{
Adnane C*, Adouly T, Taali L, Belfaquir L, Rouadi S, Abada R, Roubal M and Mahtar M \\ Department of ENT; 20 Août hospital. Ibn Rochd University Hospital, Casablanca, Morocco
}

*Corresponding author: Adnane C, Department of ENT, 20 Aout hospital, Ibn Rochd University Hospital, Casablanca, Morocco, E-mail: adnanechoaib@gmail.com

Citation: Adnane C, Adouly T, Taali L, Belfaquir L, Rouadi S, et al. (2015) Unusual Spontaneous Nasal Septal Abscess. J Case Rep Stud 3(3): 302. doi: 10.15744/2348-9820.3.302

Received Date: December 19, 2014 Accepted Date: June 08, 2015 Published Date: June 10, 2015

\begin{abstract}
A nasal septal abscess (NSA) is defined as a collection of pus between the cartilage or bony septum and the mucoperichondrium or mucoperiostium. It's an uncommon disease that in the absence of early diagnosis and proper management may lead to lethal complications and cosmetic deformity. The most common presentation of the nasal septal abscess is nasal obstruction and pain. We present a healthy patient with idiopathic spontaneous nasal septal abscess who complained of acute complete nasal obstruction and nasal pain.
\end{abstract}

Keywords: Nasal Septum; Abscess; Emergencies; Nasal deformation

\section{Introduction}

The nasal septum is an essential structure maintaining the external shape and function of the nose [1-3]. Nasal septal abscess (NSA) is defined as a collection of pus between the cartilaginous or bony nasal septum and the mucoperichondrium or mucoperiosteum [3]. It's an uncommon condition that most commonly develops in a pre-existing septal hematoma with usually a history of nasal trauma [4]. NSA is also less frequently associated with nasal furunculosis, sinusitis, influenza, dental infection, and after nasal septal surgery [3,5-7]. The cerebral spread of infection from NSA could be a lethal complication. Other complications include saddle nose deformity, septal perforation, and permanent nasal obstruction $[3,5,8]$. For this reason, early diagnosis and proper management are necessary to prevent the potentially dangerous complications and the development of severe functional and structural deformities in the future [5]. This case report presents an uncommon case of spontaneous NSA in an immunocompetent patient, to alert physicians to be more vigilant about this uncommon disease.

\section{Case report}

A 35-year-old male presented to our emergency department with symptoms of nasal and facial pain, and nasal obstruction, which he had experienced for five days. There was no prior history of nasal surgery, trauma, sinusitis, epistaxis, or dental procedures. No medical history or immunocompromised states were noted. Physical examination revealed swollen and tender nasal dorsum. Anterior rhinoscopy found bilateral purple septal swelling with total obliteration of the nasal airway (Figure 1). The nasal septal swelling did not change in size when topical nasal decongestant was applied. The diagnosis of nasal septal abscess was confirmed by needle aspiration of pus. The sample was sent for culture and sensitivity testing. The rest of the examination was unremarkable. Urgent post-contrast computed tomography (CT) scan revealed a $3 \mathrm{~cm} \times 1 \mathrm{~cm} \times 1.9 \mathrm{~cm}$ hypodense bilateral collections at the anterior nasal septum (Figure 2). Dental examination could not identify any infection. Emergency transnasal drainage of the abscess under general anesthesia was performed with bilateral septal incision and drainage. A gauze drain was placed in the abscess cavity and the nasal cavities were packed during 48 hours. Bacteriological culture found a Staphylococcus aureus that was sensitive to Amoxicillin/clavulanic acid. Patient was treated with Amoxicillin/clavulanic acid, decongestants, anti-inflammatory and analgesics for 2 weeks. Follow up at 2 weeks and one month showed intact nasal septum without any defects and complete resolution of the abscess. The abscess had nearly disappeared on CT scan. At 6 months later, there was no nasal deformity.

\section{Discussion}

The incidence of nasal septal abscess is rare; major centers reported fewer than 10 cases per year [3,9]. This entity was first reported in 1810 by Arnal [10]. Ambus et al reported 16 cases occurring over 10 years at the Massachusetts eye and ear infirmary [3]. Canty and Berkowitz reported 20 cases of nasal septal abscess in a period of 18 months [8]. Naik reported 20 cases over 54 months [11]. NSA most frequently develops in a pre-existing septal hematoma with usually a history of nasal trauma [3,4,12]. It is usually seen in younger patients and less frequently associated with nasal furunculosis, sinusitis, influenza, dental infection, and after nasal septal surgery [3,5-7]. A spontaneous idiopathic NSA is far less common. In the literature, there are very few cases of idiopathic nasal septal abscesses reported previously. According to Chung et al, there are only three idiopathic nasal septal abscesses reported previously $[13,14]$. Most of the abscess cavity situated at the anterior cartilaginous nasal septum, posterior localization may be missed if only anterior rhinoscopy is performed [15]. 


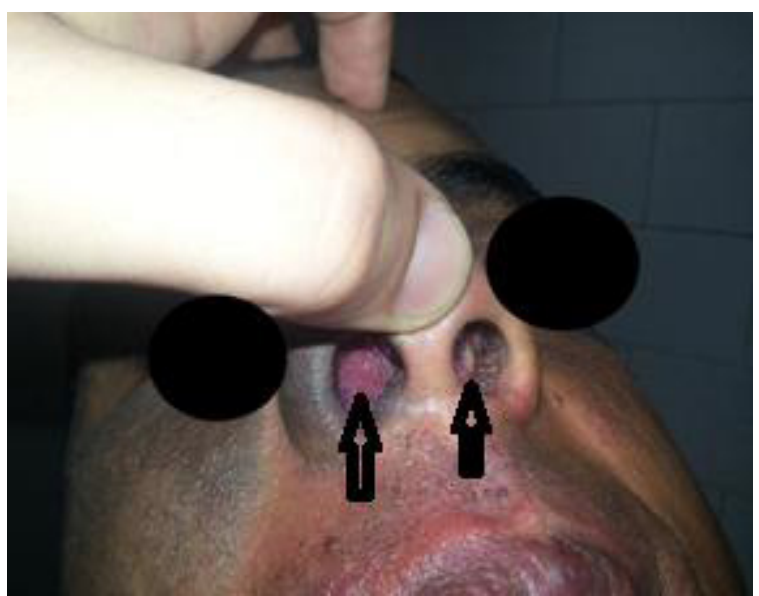

Figure 1: Bilateral purple bulging of the nasal septum
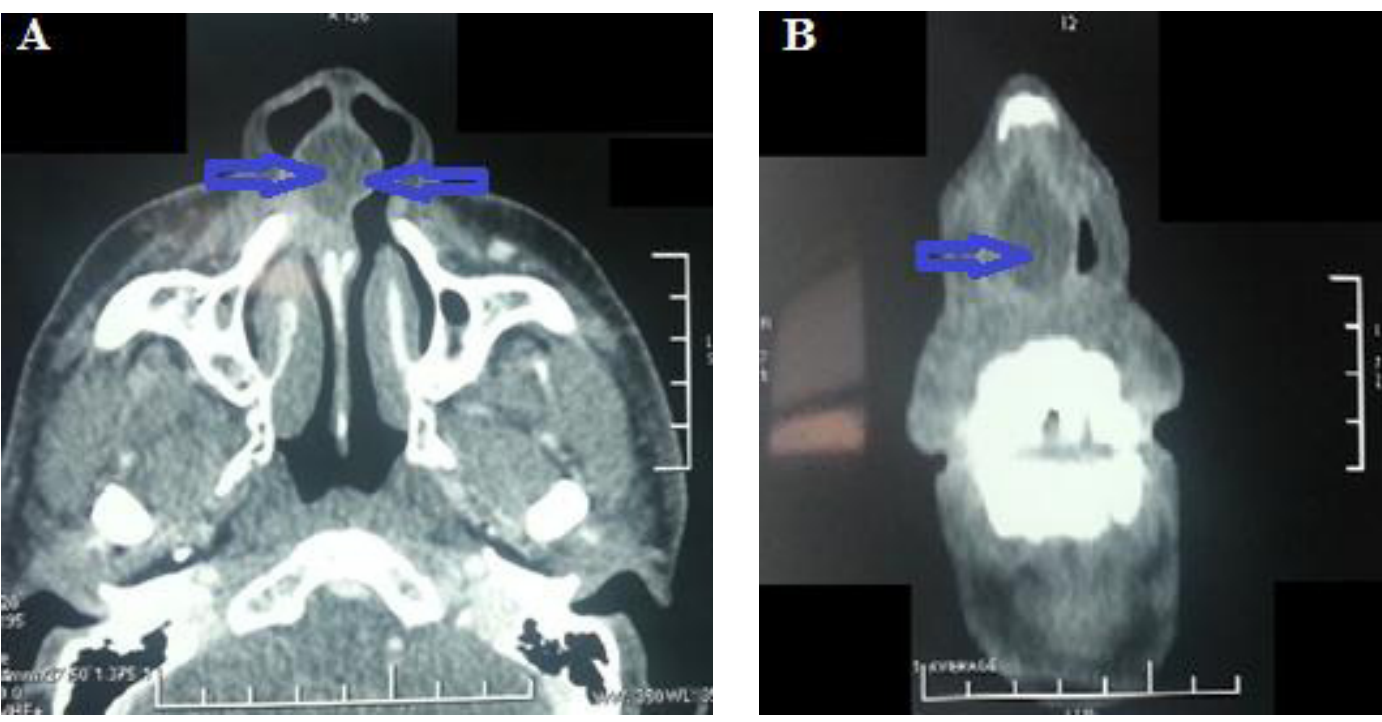

Figure 2: Computer tomographic scan: (A) Axial computed tomography image showing swelling of the nasal septum with hypodense fluid collection (B) Coronal cut showing showing septal abscess

The most common presentation of the NSA is nasal obstruction and pain [10]. In contrast, septal hematoma usually presents as painless nasal obstruction after injury. Other signs and symptoms include headache, fever, saddle nose, and swelling of the nasal septum [3]. On anterior rhinoscopy, this uncommon disease is often mistaken as nasal septal deviation or inferior turbinate hypertrophy by less experienced physicians $[10,15]$. Therefore, cautious palpation with fine-needle aspiration as need as possible may be helpful for diagnosis. CT scan with contrast enhancement is very helpful for the diagnosis, the involved area and cartilage status.

The accumulation of pus between the cartilage and perichondrium will lead to ischemia and necrosis of the cartilage; this may result in septal cartilage destruction, saddle nose deformity, functional dysfunction and cosmetic problems [16]. In children in particular, these consequences may be affect the normal development of the nose and maxilla [16,17]. Life-threatening intracranial complications; such as brain abscess, meningitis and cavernous sinus thrombosis; especially in the immunocompromised patients may progress rapidly if the NSA remains untreated $[10,13,15,18]$.

Emergency surgical drainage of nasal septal abscess and intravenous antibiotic administration is required. The abscess can be drained by a horizontal incision from behind forwards across the swollen area, as low as possible in the septum [4]. Bilateral drainage is only necessary if the abscess is bilateral with an intact septal cartilage, so that cartilage still exists between the collections of purulent material on both sides. It is sometimes advantageous to remove a piece of mucoperichondrium to facilitate drainage [19]. Some authors prefer to use a vertical or L-shaped incision in the mucoperichondrium [20]. A wick is placed in the incision, and the mucoperichondrium is replaced against the cartilage by supportive intranasal packing [21].

The most common etiological agent is Staphylococcus aureus [22], others less frequently include Streptococcus pneumoniae, group A beta hemolytic Streptococcus, anaerobes, Hemophilus influenzae [3,23]. Opportunistic fungal agents have been reported in HIV patients resulting in a high mortality $[10,24]$. Empirical antibiotic treatment must be started immediately once diagnosis is made before the organism is isolated. 
In case of nasal deformity after septal destruction, reconstruction of the nasal septum may be performed immediately after drainage of the abscess as a primary treatment, or secondary treatment after resolution of the infection [16,18]. Reconstruction of the septal cartilage may be used by residual septal cartilage or autologous cartilage grafts from tragus, auricle or rib [16,17].

\section{Conclusion}

Nasal septal abscess is an uncommon rhinological emergency disease. Because of its non specific symptoms, careful examination with detailed history is essential especially in the non-traumatic context. Early management would prevent nasal deformity and intracranial complications.

\section{References}

1. Grymer LF, Bosch C (1997) The nasal septum and the development of the midface. A longitudinal study of a pair of monozygotic twins. Rhinology 35: 6-10.

2. Nolst Trenité GJ, Verwoerd CD, Verwoerd-Verhoef HL (1988) Reimplantation of autologous septal cartilage in the growing nasal septum. II. The influence of reimplantation of rotated or crushed autologous septal cartilage on nasal growth: an experimental study in growing rabbits. Rhinology 26: 25-32.

3. Ambrus PS, Eavey RD, Baker AS, Wilson WR, Kelly JH (1981) Management of nasal septal abscess. Laryngoscope 91(4): 575-82.

4. Fearon B, Mckendry Jb, Parker J (1961) Abscess of the nasal septum in children. A case history of meningitis secondary to a septal abscess. Arch Otolaryngol 74: 408-12.

5. Matsuba HM, Thawley SE (1986) Nasal septal abscess: unusual causes, complications, treatment, and sequelae. Ann Plast Surg 16: 161-6.

6. Pang KP, Sethi DS (2002) Nasal septal abscess: an unusual complication of acute spheno-ethmoiditis. J Laryngol Otol 116: 543-5.

7. da Silva M, Helman J, Eliachar I, Joachims HZ (1982) Nasal septal abscess of dental origin. Arch Otolaryngol 108: 380-1.

8. Canty PA, Berkowitz RG (1996) Hematoma and abscess of the nasal septum in children. Arch Otolaryngol Head Neck Surg 122: 1373-6.

9. Eavey RD, Malekzakeh M, Wright HT (1977) Bacterial meningitis secondary to abscess of the nasal septum. Pediatrics 60: 102-4.

10. Shah SB, Murr AH, Lee KC (2000) Nontraumatic Nasal Septal Abscesses in the Immunocompromised: Aetiology, Recognition, Treatment and Sequelae. Am J Rhinol 14: 39-43.

11. Naik SM, Naik SS (2010) Nasal Septal Abscess: A Retrospective Study of 20 Cases in KVG Medical College and Hospital, Sullia. Clin Rhinol: An Int J 3: 135-40.

12. Beck AL (1945) Abscess of the nasal septum complicating acute ethmoiditis. Arch Otolaryngol 42: 275-9.

13. Salam B, Camilleri A (2009) Non-Traumatic Nasal Septal Abscess in an Immunocompetent Patient. Rhinology 47: 476-7.

14. Chung J C-k, Wong A T-K, Ho W-k (2013) Spontaneous Nasal Septal Abscess Presenting as Complete Nasal Obstruction. Int J Otolaryngol Head Neck Surg 2: 79-81.

15. George A, Smith WK, Kumar S, Pfleiderer AG (2008) Posterior Nasal Septal Abscess in a Healthy Adult Patient. J Laryngol Otol 122: 1386-8.

16. Dispenza C, Saraniti C, Dispenza F, Caramanna C, Salzano FA (2004) Management of Nasal Septal Abscess in Childhood: Our Experience. Int J Pediatr Otorhinolaryngol 68: 1417-21.

17. Menger DJ, Tabink IC, Trenite GJ (2008) Nasal Septal Abscess in Children: Reconstruction with Autologous Cartilage Grafts on Polydioxanone Plate. Arch Otolaryngol Head Neck Surg 134: 842-7.

18. Cho JG, Lim HW, Zodpe P, Kang HJ, Lee HM (2006) Nasal Septal Abscess: An Unusual Presentation of Dentigerous Cyst. Eur Arch Otorhinolaryngol 263: 1048-50.

19. Thomson STC (1955) Diseases of the septum, in Diseases of the Nose and Throat: a Textbook for Students and Practitioners, (6 $6^{\text {th }}$ rev edn) Negus VE, Bateman GH (eds), Cassell, London.

20. Simon RR, Brenner BE (2002) Emergency Procedures and Techniques ( $4^{\text {th }}$ ed). Philadelphia, United States.

21. Fry HJ (1969) The pathology and treatment of haematoma of the nasal septum. Br J Plast Surg 22: 331-5.

22. Jalaludin MA (1993) Nasal Septal Abscess--Retrospective Analysis of 14 Cases from University Hospital, Kuala Lumpur. Singapore Medical Journal 34: 435-7.

23. Huang PH, Chiang YC, Yang TH, Chao PZ, Lee FP (2006) Nasal Septal Abscess. Otolaryngol Head Neck Surg 135: 335-6.

24. Walker R, Gardner L, Sindwani R (2007) Fungal Nasal Septal Abscess in the Immunocompromised Patient. Otolaryngol Head Neck Surg 136: 506-7.

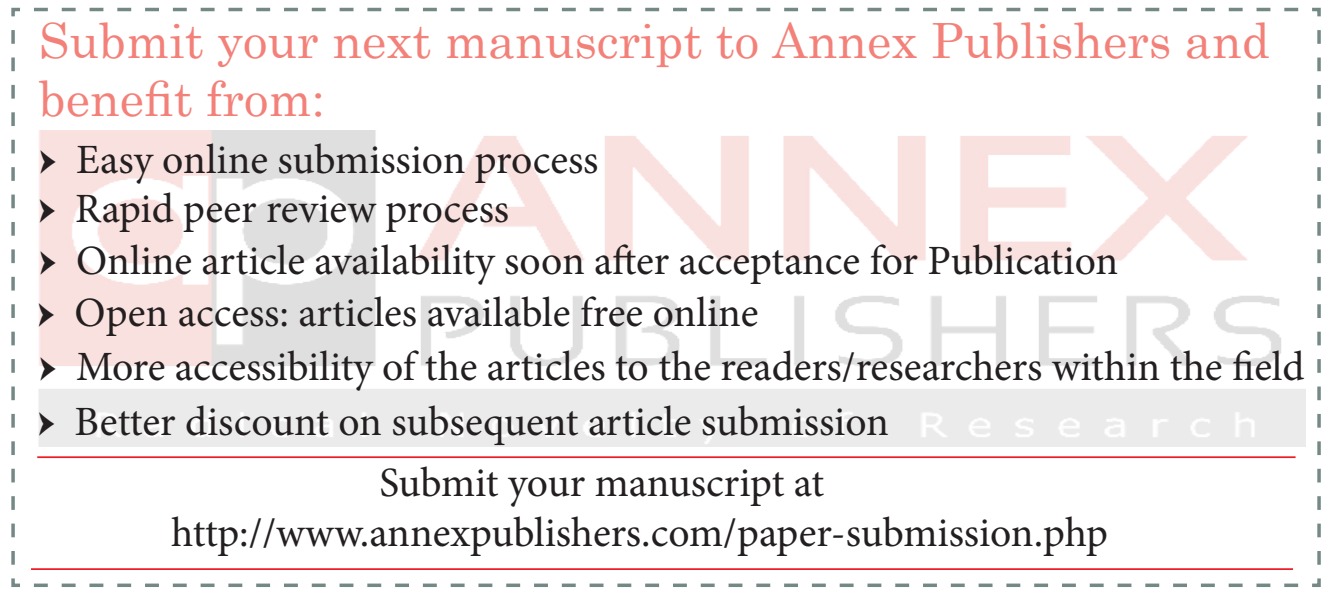

